\title{
Impact Of Paternalistic Leadership On Employees' Outcome - A Study On The Banking Sector Of Pakistan
}

\author{
Habiba Anwar \\ Foundation University Islamabad, Pakistan
}

\begin{abstract}
The main purpose of this research article is to find out the impact of paternalistic leadership on the employee's outcome in the banking sector of Pakistan. From the previous researches it is speculated that paternalistic leadership and employee outcome have a positive connection. For data collection questionnaire and convenient sampling method was used. 260 questionnaires were filled in total. 5 point likert scale (strongly agree to strongly disagree) was used. Correlation and Multiple regression analysis were done on SPSS software (SPSS Inc, 2000). The end result proved that the benevolent leadership has a positive impact on the job satisfaction of the employees, organizational commitment and innovative behavior. Authoritative leadership has a positive effect on the motivation level of the employees at work. Moral leadership doesn't have any positive or negative collision on employee's outcome. At the end it is proved that paternalistic leadership has a positive impact on employee outcome.
\end{abstract}

\section{Introduction}

Ravasi and Schultz (2006) studied organizational culture in detail and concluded that it is on the basis of the culture the organizations outcome will be decided. Organization culture has a strong impact on the outcome of the organization. It tells you when and where how one should react and how to tackle different situations. They also said that in one organization it might be possible that two different cultures are prevailing. This can due to different perspectives of two different teams. The culture of the organization has positive as well as negative aspects. These aspects will directly affect the outcome of an organization.

An important factor in the organizations is the style of leadership in that organization. Being a leader is all about having followers, having the ability to influence others and guiding them what's best for them. The leader will choose the style which he/she will think is best. It will be based on their own experience, personality and the principles of their own lives. The type of leadership also depends upon the culture of that organization (Max Weber, 1947). Round about 8 decades ago different researchers came to this conclusion that if the leaders/managers focus more on employees rather than the procedures than employees will be more satisfied and than their output will be at the higher level.

Paternalistic leadership means the leader will behave like a father with the followers. He/she will take care of the employees and help them in every way possible. The leader will be concerned about the employees and due to this concern the employees will remain loyal to the leader and organization. The leader will try to sort out the personal problems of the employees as well because if the employee has got some issues at home then he/she can't focus on work properly so it's necessary to sort out that issue. Farh and Cheng (2000) have searched about the paternalistic leadership in detail. They studied the previous researches and then they explained paternalistic leadership in their own definition as a leadership style in which the leaders will have a strong influence on their employee. The leader will give the employees a platform where they can give their idea but at the end mutual decision will be taken. They will keep their control over the employees but let them be innovative as well. If we study this definition in detail we will get to know that there are three main components of paternalistic leadership which are authoritarianism, benevolence/kindness and moral leadership.

Authoritarianism means having a control over the employees. They cannot make a decision on their own without even consulting you. Benevolent means have a good relationship with employees. Dealing with them with care and create a friendly working environment. When the employees will be satisfied it will be shown in their work output. Their work output will at the end benefit the outcome of the organization. The last important aspect is the moral leadership in which the leader follows the norms and principles, make fair and ethical decisions so that others would also follow the same pattern. Through this the overall organization will become ethical and everyone will be happy to work there.

\subsection{Problem statement}

The problem statement of this article is to check the influence of paternalistic leadership on the outcome of the employees. 


\subsection{Objectives of the research}

The objective of this article is to get to know about the connection between paternalistic leadership with the outcome of the employees in the banking sector of Pakistan. How paternalistic leadership is benefiting the organizational outcome and in which ways it can be destructive for an organization.

\subsection{Significance of the research}

The main significance of the research is that it will help the organizations to adopt a leadership style which will be beneficial for them in form of higher productivity. Leaders are the once who motivate and can demotivate the workforce so it's important to choose the best and effective leadership style. This study will help to know about paternalistic leadership in detail and what are its effects on the outcome of an employee.

\section{Literature Review}

Gauraz Akrani (2009) concluded that the paternalistic leader helps his/her sub-ordinates. The leader will create an environment in the organization which will be friendly and the leader will behave like a father with the employees. He will not just remain concerned about the work problems of employees but he will also discuss their personal issues so that they can put $\mathrm{n}$ their best efforts. Max Weber (1968) defined Paternalistic leadership term is now recently being used but if we look at the past about 8 decades ago Max Weber explained the theory of paternalism. He explained three types of leadership one was traditional, other one was charismatic and the last one was bureaucratic. In the traditional one he explained it as a parental leadership. (Westwood and clan (1992) explained paternalism leadership as a relationship between parents and their children's. In this relation authority always remains with the parent but the parent will never use it in a wrong way. This relationship is about care and kindness. Paternalistic leadership is about a bond among the leader and the employees in which they follow their leader and do work with great enthusiasm. This is because of the relationship they have among each other (Aycan et al., 2000; Pellegrini \& Scandura, 2006).

According to Bor-Shiuan Cheng (2004) checked the employees view that what they think about the paternalistic leadership. The results of this research show that all the components of paternalistic leadership have a good effect and encourage the employees in a positive manner. The kindness of the leader is the most important for the employees. Employees will get encouraged and will copy as it is their leaders. But the results showed that moral leadership s the one which has huge influence on the employees.

According to Hodgetts, Richard M. \& Luthans, Fred (2003) in authocratic leadership all the employees have to act upon what the leader said. Each and every order of the leader has to be followed. It is necessary for the employees to follow the exact orders and don't object unnecessarily. Employees can give their opinions and ideas but the end decision will be of the leader. In benevolent leadership all the leaders should be kind and show care for their employees. This will make the employees and the leader to work together with unity and incorporation. In moral leadership the leaders are the role model for all the employees. Whatever they do is followed by the subordinates. The leader should be kind and fair with everyone.

Chen \& Silverthrone (2005) and Spector (1997) have explored about the job satisfaction factors of the employees. They concluded that it depends on the bonding between the leader and employees. This bond will tell that whether employees are satisfied or dissatisfied. They also said that the work environment also plays an important role in the satisfaction level of the employees. Leaders who will have stong relationship with his/her employees will have a more motivted work force and the employees job satisfaction level will be at its highest level (Madlock, 2008).

Soili Vesterinen, Marjo Suhonen, Arja Isola,and Leena Paasivaara concluded that devotion of the nurse managers, their input for the success and the satisfaction level of all the patients are related with one another and have a healthy impact on the organization. But if the nurse managers just see their association with the organization than it will definitely affect the outcome which is the satisfaction level of the patients. So it will have a bad affect on the reputation of the organization.

(Aycan, 2001) concluded that Paternalistic leadership is all about being kind to the employees. Treating them in a polite manner and behave with them as a father. Leader will think about the well being of employee. $\mathrm{He} / \mathrm{she}$ will try to solve their problems (work related as well as personal), than the employees will be follow the orders and will be faithful to the leader and the organization. Paternalistic leadership does not mean that the leader will always be good and polite with the employees even if they are doing a wrong act. They can scold and be harsh with them when they have done something wrong. After the analysis the results showed that it is necessary for the employees to be faithful and devoted with the organization. Some said that the employees shouldn't even leave the organization for a better option.

From the above discussion following hypotheses are concluded along with the scamatic diagram: 


\subsection{Theoretical framework}

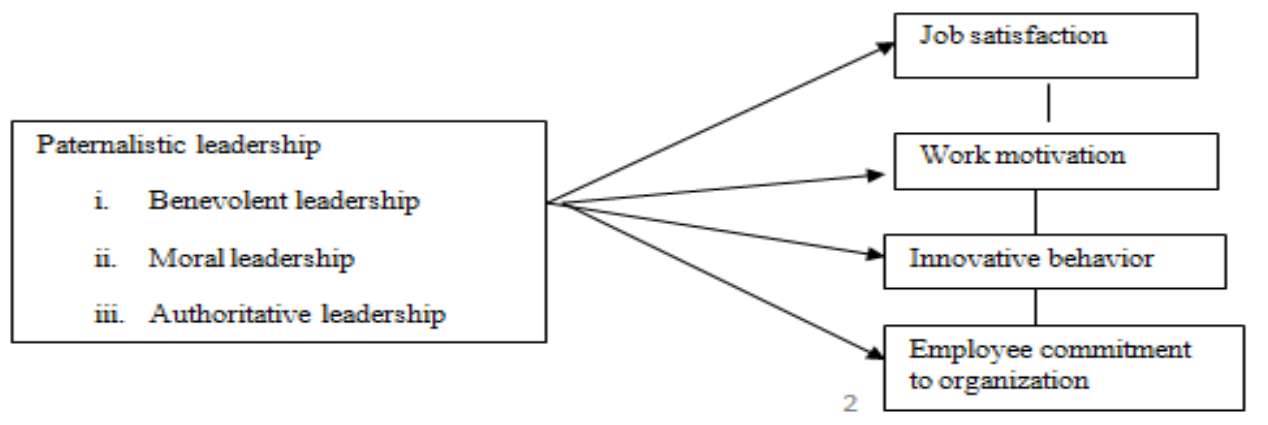

Hypothesis $1\left(\mathrm{H}_{\mathbf{1}}\right)$

Paternalistic leadership (PL) has a constructive and beneficial impact on the outcome of the employees.

Hypothesis $2\left(\mathbf{H}_{2}\right)$

Benevolent leadership has a constructive effect on the innovative attitude of the employees.

Hypothesis $3\left(\mathbf{H}_{3}\right)$

Moral leadership has a constructive effect on the innovative attitude of the employees.

Hypothesis $4\left(\mathbf{H}_{4}\right)$

Authoritative leadership has a constructive effect on the innovative attitude of the employees.

Hypothesis 5 ( $\left.\mathbf{H}_{5}\right)$

Benevolent leadership has affirmative impact on the commitment of the employees towards the organization.

Hypothesis $6\left(\mathrm{H}_{6}\right)$

Moral leadership has affirmative impact on the commitment of the employees towards the organization.

Hypothesis $7\left(\mathbf{H}_{7}\right)$

Authoritative leadership has affirmative impact on the commitment of the employees towards the organization.

Hypothesis $8\left(\mathbf{H}_{8}\right)$

Benevolent leadership has a direct effect on the job satisfaction of employee.

Hypothesis 9 ( $\left.\mathbf{H}_{9}\right)$

Moral leadership has a direct effect on the job satisfaction of employee.

Hypothesis $10\left(\mathrm{H}_{10}\right)$

Authoritative leadership has a direct effect on the job satisfaction of employee.

Hypothesis $11\left(\mathrm{H}_{11}\right)$

Benevolent leadership has influential impact on the work motivation of an employee.

Hypothesis $12\left(\mathrm{H}_{12}\right)$

Moral leadership has influential impact on the work motivation of an employee.

Hypothesis $13\left(\mathrm{H}_{13}\right)$

Authoritative leadership has influential impact on the work motivation of an employee.

\section{Research Methodology}

In this research I have chosen the banking sector as banks are the main financial part of a country. I checked out whether the banks are applying paternalistic leadership or not and if they are applying than what are the effects of paternalistic leadership on the outcome of the employees of that organization. For the data collection I have chosen four banks of Rawalpindi and Islamabad which are as follows:

1. MCB bank limited

2. Allied bank limited

3. Alfalah bank limited

4. Standard chartered bank limited

As for this research the banking sector of Pakistan was chosen. It's not possible to gather the data from each and every bank of Pakistan. So for the sample size only four banks were chosen from Rawalpindi and Islamabad. As the researcher had an access to the banks in Rawalpindi and Islamabad as they were nearby so data collection was easy. Total sample size of the research is 260 employees. Only those employees of the banks were given the questionnaires that have more than 3 years of experience in the banking sector.

At the end when the researcher gets the questionnaire back than the data analysis was done through the software which is SPSS and version 2000 of SPSS was used for the analysis. Two analyses were done; one was correlation and second was regression to get to know the relation of paternalistic leadership with the outcome of an employee. 


\subsection{Testing of the hypothesis}

\section{Data Analysis}

The researcher has developed 13 hypotheses which need to be tested. One by one each hypothesis is tested through regression analysis.

If we look at the model there is one independent variable which has three aspects Moral, Authoritative and benevolent style of leadership. The dependent variables are four which are actually the outcome of the employee.

For the first hypothesis linear regression analysis has been used. The first hypothesis is as follows:

Hypothesis 1: Paternalistic leadership (PL) has a constructive and beneficial impact on the outcome of the employees.

Coefficients $^{\mathrm{a}}$

\begin{tabular}{|ll|r|r|r|r|r|}
\hline \multirow{2}{*}{ Model } & \multicolumn{2}{|c|}{$\begin{array}{c}\text { Unstandardized } \\
\text { Coefficients }\end{array}$} & \multicolumn{2}{c|}{$\begin{array}{c}\text { Standardized } \\
\text { Coefficients }\end{array}$} & \\
\cline { 3 - 4 } & \multicolumn{1}{|c|}{$\mathrm{B}$} & Std. Error & \multicolumn{1}{|c|}{ Beta } & \multicolumn{1}{c|}{$\mathrm{t}$} & Sig. \\
\hline 1 & (Constant) & 2.844 & .247 & & 11.327 & .000 \\
& $\mathrm{pl}$ & .297 & .090 & .387 & 3.790 & .000 \\
\hline
\end{tabular}

a. Dependent Variable: DV

The value of the $t$ have to be above -2 or above +2 . In this analysis the value of $t$ is 3.790 which is much above than +2 . Its significant value is .000 . These values show that paternalistic leadership has constructive and beneficial impact on the outcome of the employees. In this analysis the value of Beta is .387 and the significant value is .000. It means that the independent variable has $38.7 \%$ impact on the dependent variables.

Hypothesis $2\left(\mathbf{H}_{2}\right)$

Benevolent leadership has a constructive effect on the innovative attitude of the employees.

Hypothesis $3\left(\mathbf{H}_{3}\right)$

Moral leadership has a constructive effect on the innovative attitude of the employees.

Hypothesis $4\left(\mathbf{H}_{4}\right)$

Authoritative leadership has a constructive effect on the innovative attitude of the employees.

Coefficients $^{\mathrm{a}}$

\begin{tabular}{|c|c|c|c|c|c|c|}
\hline \multirow{2}{*}{\multicolumn{2}{|c|}{ Model }} & \multicolumn{2}{|c|}{$\begin{array}{l}\text { Unstandardized } \\
\text { Coefficients }\end{array}$} & \multirow{2}{*}{$\begin{array}{c}\text { Standardized } \\
\text { Coefficients }\end{array}$} & \multirow[b]{2}{*}{$t$} & \multirow[b]{2}{*}{ Sig. } \\
\hline & & $B$ & Std. Error & & & \\
\hline & (Constant) & 3.635 & .408 & & 8.177 & .000 \\
\hline & $\mathrm{BL}$ & .085 & .087 & .163 & 1.377 & .206 \\
\hline & ML & .009 & .076 & .023 & .119 & .923 \\
\hline & $A L$ & -.008 & .101 & -.008 & -.079 & .923 \\
\hline
\end{tabular}

a. Dependent Variable: IB

If we look at the beta value in the above table we will see that for benevolent and moral leadership the value is positive but for authoritative leadership it is negative. When we compare the benevolent and moral leadership beta value we will get that benevolent has the highest positive value. It means that when a leader is being kind and showing care towards the employees than the employee will be creative at the maximum level. He / she will show creativity when the leader will be using moral leadership style. On the other hand authoritative leadership style has a negative impact on the creativity of an employee.

Hypothesis $5\left(\mathbf{H}_{5}\right)$

Benevolent leadership has affirmative impact on the commitment of the employees towards the organization.

Hypothesis $6\left(\mathrm{H}_{6}\right)$

Moral leadership has affirmative impact on the commitment of the employees towards the organization.

Hypothesis $7\left(\mathbf{H}_{7}\right)$

Authoritative leadership has affirmative impact on the commitment of the employees towards the organization. 


\section{Coefficients $^{\mathrm{a}}$}

\begin{tabular}{|c|c|c|c|c|c|c|}
\hline \multirow{2}{*}{\multicolumn{2}{|c|}{ Model }} & \multicolumn{2}{|c|}{$\begin{array}{l}\text { Unstandardized } \\
\text { Coefficients }\end{array}$} & \multirow{2}{*}{$\begin{array}{l}\text { Standardized } \\
\text { Coefficients } \\
\text { Beta }\end{array}$} & \multirow[b]{2}{*}{$\mathrm{t}$} & \multirow[b]{2}{*}{ Sig. } \\
\hline & & $B$ & Std. Error & & & \\
\hline \multirow[t]{4}{*}{$\overline{1}$} & (Constant) & 3.308 & .326 & & 6.069 & .000 \\
\hline & $\mathrm{BL}$ & .305 & .069 & .473 & 4.461 & .002 \\
\hline & ML & -.061 & .067 & -.087 & -.801 & .380 \\
\hline & $\mathrm{AL}$ & .336 & .070 & .380 & 3.954 & .003 \\
\hline
\end{tabular}

a. Dependent Variable: oc

In the above table the beta value of the benevolent leadership is positive. It shows that it has an affirmative impact on the commitment of the employees towards the organization. When the leader will be kind to the employees than the employees will be loyal to the supervisor as well as to the organization. If we see the beta value of the moral leadership it is negative. It means that moral leadership does not increase the commitment of the employees towards the organization. Authoritative leadership has a positive impact on the commitment level of the employees towards the organization. In the above table it is shown that benevolent leadership has the highest beta value means that it has the highest affirmative impact on the commitment level of the employees.

\section{Hypothesis $8\left(\mathbf{H}_{8}\right)$}

Benevolent leadership has a direct effect on the job satisfaction of employee.

\section{Hypothesis $9\left(\mathbf{H}_{9}\right)$}

Moral leadership has a direct effect on the job satisfaction of employee.

\section{Hypothesis $\mathbf{1 0}\left(\mathbf{H}_{10}\right)$}

Authoritative leadership has a direct effect on the job satisfaction of employee.

\section{Coefficients $^{\mathrm{a}}$}

\begin{tabular}{|ll|r|r|r|r|r|}
\hline \multirow{2}{*}{ Model } & \multicolumn{2}{|c|}{$\begin{array}{c}\text { Unstandardized } \\
\text { Coefficients }\end{array}$} & \multicolumn{2}{c|}{$\begin{array}{c}\text { Standardized } \\
\text { Coefficients }\end{array}$} & \\
\cline { 3 - 5 } & \multicolumn{1}{|c|}{$\mathrm{B}$} & Std. Error & \multicolumn{2}{|c|}{ Beta } & \multicolumn{1}{c|}{ Sig. } \\
\hline 1 & (Constant) & 3.388 & .714 & & 4.345 & .001 \\
& $\mathrm{BL}$ & .315 & .140 & .370 & 3.346 & .031 \\
& $\mathrm{ML}$ & .097 & .144 & .099 & .796 & .542 \\
& $\mathrm{AL}$ & .028 & .165 & .037 & .119 & .967 \\
\hline
\end{tabular}

a. Dependent Variable: Sat

In the above table the beta values of all three leadership styles are positive. It means that all three of them have a direct effect on the job satisfaction of an employee. The beta values show that benevolent leadership has the highest value, which means that it has a greater impact on the job satisfaction of employee than the moral and authoritative style of leadership. The authoritative style of leadership has the lowest beta value, which means that it has less impact on the satisfaction level of the employee.

Hypothesis $11\left(\mathbf{H}_{11}\right)$

Benevolent leadership has influential impact on the work motivation of an employee.

Hypothesis $12\left(\mathrm{H}_{12}\right)$

Moral leadership has influential impact on the work motivation of an employee.

Hypothesis $13\left(\mathrm{H}_{13}\right)$

Authoritative leadership has influential impact on the work motivation of an employee. 
Coefficients $^{\mathrm{a}}$

\begin{tabular}{|c|c|c|c|c|c|c|}
\hline \multirow{2}{*}{\multicolumn{2}{|c|}{ Model }} & \multicolumn{2}{|c|}{$\begin{array}{c}\text { Unstandardized } \\
\text { Coefficients }\end{array}$} & \multirow{2}{*}{$\begin{array}{c}\text { Standardized } \\
\text { Coefficients } \\
\text { Beta }\end{array}$} & \multirow[b]{2}{*}{$t$} & \multirow[b]{2}{*}{ Sig. } \\
\hline & & $B$ & Std. Error & & & \\
\hline \multirow[t]{4}{*}{1} & (Constant) & 3.469 & .438 & & 5.738 & .000 \\
\hline & $\mathrm{BL}$ & .055 & .090 & .075 & .576 & .583 \\
\hline & $\mathrm{ML}$ & -.092 & .086 & -.145 & -1.199 & .248 \\
\hline & $A L$ & .358 & .117 & .346 & 3.343 & .003 \\
\hline
\end{tabular}

a. Dependent Variable: WM

In the above table the beta value of benevolent and authoritative leadership are positive while the moral leadership value is negative. It means that when the leaders are kind and have some control over their employees than it will increase the motivation level of the employees. Moral leadership does not increase the motivation level. Another important thing is authoritative leadership got the highest beta value which means that it has strong impact on the work motivation level of employees than the other two leadership styles.

\section{Conclusion}

It has been proved that the leaders should be caring to their employees, behave in a kind manner with them, they should try to solve the problems even the personal problems. As when someone is having problems at home their work will be affected due to this. One can't give their best when their mind is deviated. So it's the leader who should do counseling of the employees. Try to solve their problems and make the work environment as friendly and cooperative. Everyone should be concerned about others. A leader should be authoritative but not too much because it will lessen the creativity level of the employees and they will not be able to bring innovative ideas. Control is important but with kindness and care.

Benevolent leadership has the most positive impact on the employees and moral leadership has does not increase the motivational level of the employees. The employees are inspired from their leaders they think their leaders are the best but even then they think they can't be like them because from their point of view the leaders are living and enjoying a very different life from them. Their life is much easier than theirs. They do not have to fight with the daily issues which make them distractive and de-motivated. Only the benevolent leadership is the one which has a positive effect on all the dependent variables.

\section{References}

[1] Aycan, Z. (2001). Paternalistic leadership. Journal of management studies. 10-33.

[2] Chao, Chih-Yang. Y.-S. L.-L.-C. (2011). Employee innovation, supervisory leadership, organizational justice, and organizational culture in Taiwan's manufacturing industry. African Journal of Business Management. Vol.5 , 2505-2516.

[3] Cheng, Bor-Shiuan. L.-F. C.-Y.-P.-L. (2004). Paternalistic leadership and subordinate responses: Establishing a leadership model in Chinese organizations. Asian Journal of Social Psychology , 85-120.

[4] Chen,Xiao-Ping. B, Marion. E. Chiang, Ting-Ju. Farh, Jiing-Lih. Cheng, Bor-Shiuan.(2011, June). Affective Trust in Chinese Leaders: Linking Paternalistic Leadership to Employee Performance Journal of Management. Vol 5

[5] Farh, J. L. Cheng, B. S. (2000). A cultural analysis of paternalistic leadership in Chinese organizations. Management and organizations in the Chinese Context. pp. 92-130.

[6] Freeman, R. Edward. Stoner, James A. (1992). Management 5 Edition. Englewood Cliffs: Prentice Hall. Vol 3

[7] Foong Loke, J Chiok. (2001,August). Leadership behaviours: effects on job satisfaction, productivity and organizational commitment Nanyang Polytechnic, School of Health Sciences/Nursing, Singapore. Journal of Nursing Management (impact factor: 1.18). 9(4):191-204.

[8] Guneser, G. S. (2008). The relationship between paternalistic leadership and organizational commitment: investigating the role of climate regarding ethics. Journal of Business Ethics , 950-970.

[9] Hodgetts. M, Richard. Luthans and Fred. (2003). Mc Graw-Hill international management- culture, strategy and behavior. P 1837.

[10] J,Chen. C,Silverthorne. (2005). "Leadership Effectiveness, Leadership Style and Employee Readiness." Leadership and Organizational Development Journal. 26(4), 280-288.

[11] K, Ekin. Pellegrini. A,Terri. (2008, June). Scandura Journal of Management. vol. 34, 3: pp. 566-593.

[12] K, Ekin. Pellegrini. A, Terri. (2010, August). Cross-Cultural Generalizability of Paternalistic Leadership: An Expansion of Leader-Member Exchange Theory. Scandura, and Vaidyanathan Jayaraman Group \& Organization Management; vol. 35, 4, pp 391-420.

[13] Paoching, C. a. (2010, December). The Journal of Global Business Management: Previous Issue, Volume 6* Number 2* December 2010. Retrieved November 6, 2011, from www.jgbm.org

[14] Paul E, Madlock. (2008). "The Link Between Leadership Style, Communicator Competence, And Employee Satisfaction", Journal of Business Communication. Volume 45, Number 1, pp. 61-78.

[15] Pellegrini, E. K. Scandura, T. A. (2006). Leader-member exchange (LMX), paternalism and delegation in theTurkish business culture: An empirical investigation. Journal of International Business Studies, 37(2): 264-279. 
[16] Ravasi, D. Schultz, M. (2006). Responding to organizational identity threats: exploring the role of organizational culture. Academy of Management Journal, Vol.49, No.3, pp 433-458.

[17] Soili Vesterinen, Marjo Suhonen, Arja Isola,and Leena Paasivaara. Nursing Research and Practice Volume 5, 2012 (2012), Article ID 605379, 8 pages doi:10.1155/2012/605379

[18] Spector, P. E. (1997). Job satisfaction: Application, assessment, causes, and consequences. London. Pg 30-67

[19] Weber, M. (1947). The theory of social and economic organization (A. M. Henderson \& T. Parsons, Trans.). New York: Free Press. P 60-87.

[20] Weber, M. (1968). The types of legitimate domination. In G. Roth \& C. Wittich (Eds.), Economy and society. Vol.3, $212-216$.

[21] Westwood, R. Chan, A. (1992). Headship and leadership. In R. Westwood (Ed.), Organisational behaviour:Southeast Asian perspectives: 118-143.

[22] Wu, Min. Haung, Xu. Li, Chenwei. (2004). Perceived Interactional Justice and Trust-in-supervisor as Mediators for Paternalistic Leadership.Sichuan University, China. P 15-35. 